\title{
Arrhythmogenic Right Ventricular Cardiomyopathy and Heart Transplantation: Two Cases \\ Gesaro $\mathrm{GD}^{1^{*}}$, Minà $\mathrm{C}^{1}$, Ruperto $\mathrm{C}^{1}$, Liotta $\mathbf{R}^{2}$, Scardulla $\mathbf{C}^{1}$ and Clemenza $\mathrm{F}^{1}$ \\ ${ }^{1}$ Cardiology Unit, Department for the Study and Treatment of Cardiothoracic Diseases and for Cardiothoracic Transplants, IRCCS - ISMETT, Palermo, Italy \\ ${ }^{2}$ Pathology Unit, Department of Diagnostic and Therapeutic Services, IRCCS - ISMETT, Palermo, Italy
}

"Corresponding authors: Gesaro GD, Cardiology Unit, Department for the Study and Treatment of Cardiothoracic Diseases and for Cardiothoracic Transplants, IRCCS - ISMETT, Palermo, Italy, Tel: +393294225215; Fax: +390912192400; E-mail: gdigesaro@ismett.edu

Received date: Nov 20, 2015; Accepted date: Jan 07, 2016; Published date: Jan 09, 2016

Copyright: $\odot 2016$ Gesaro GD, et al. This is an open-access article distributed under the terms of the Creative Commons Attribution License, which permits unrestricted use, distribution, and reproduction in any medium, provided the original author and source are credited.

\begin{abstract}
Arrhythmogenic right ventricular cardiomyopathy (ARVC) is a myocardial disease characterized by fibrofatty replacement. The main clinical features are sudden death due to ventricular arrhythmias and congestive heart failure. Diagnosis of ARVC is still problematic and frequently made only by autopsy. Criteria for orthotropic heart transplant $(\mathrm{HTx})$ have still not well been defined. We present two cases of arrhythmogenic right ventricular cardiomyopathy who underwent heart transplant. They demonstrate that heart transplant can be a real therapeutic option for these patients and offer to us the possibility to confirm the diagnosis and better understand pathological and histological features of the disease.
\end{abstract}

Keywords: Heart Transplantation; Heart failure; Cardiomyopathy; Cardiac anatomy/pathologic anatomy; Heart failure operations

\section{Case Report}

\section{Case 1}

This is a 62 years-old-male affected from 1987 by ARVC characterized by recidivant episodes of supraventricular and ventricular tachycardia treated with amiodarone, cardioverter defibrillator implantation and transcatheter ablation over time.

In March 2011 he was admitted in our institution for dyspnea after mild effort and signs of right heart decompensation (hepatomegaly, jugular distension and peripheral edema). He has optimized the medical treatment with the increase of amiodarone dose to $300 \mathrm{mg}$ die and the increase of furosemide to $175 \mathrm{mg}$ die. So he started evaluation for heart transplant. The electrocardiogram showed bradycardia and the characteristic epsilon waves (Figure 1). NT-pro-BNP was 1624 $\mathrm{pg} / \mathrm{ml}$. Right heart catheterization (RHC) showed: pulmonary artery pressure 26/16/20 $\mathrm{mmHg}$, right atrium pressure: $19 \mathrm{mmHg}$, pulmonary capillary wedge pressure: $17 \mathrm{mmHg}$, right ventricle (RV) mean pressure: $17 \mathrm{mmHg}$, cardiac output: $3,5 \mathrm{l} / \mathrm{min}$, cardiac index: 1,8 $\mathrm{m} / \mathrm{l} / \mathrm{m} 2$. At echocardiogram right ventricle resulted dilated and severely hypokinetic with apical trabeculae and hyper-reflective moderator band. Tricuspid valve had a severe regurgitation with slow velocity $(1,3 \mathrm{~m} / \mathrm{sec})$. Left ventricle $(\mathrm{LV})$ was mildly dilated with ejection fraction $40 \%$. Based on history of recidivant ventricular tachycardia and right ventricular failure with left ventricle dysfunction he entered in our heart transplant waiting list and underwent HTx in August 2011 with regular post-operative course. The explanted heart examination confirmed the clinical diagnosis of ARVC.
Gross examination revealed right ventricular dilatation. Right ventricle outflow tract appeared enlarged and transillumination highlined the wall thinning and the almost total fibro-fatty replacement of the myocardium. Focal areas of endocardial fibrosis were seen in both ventricles.

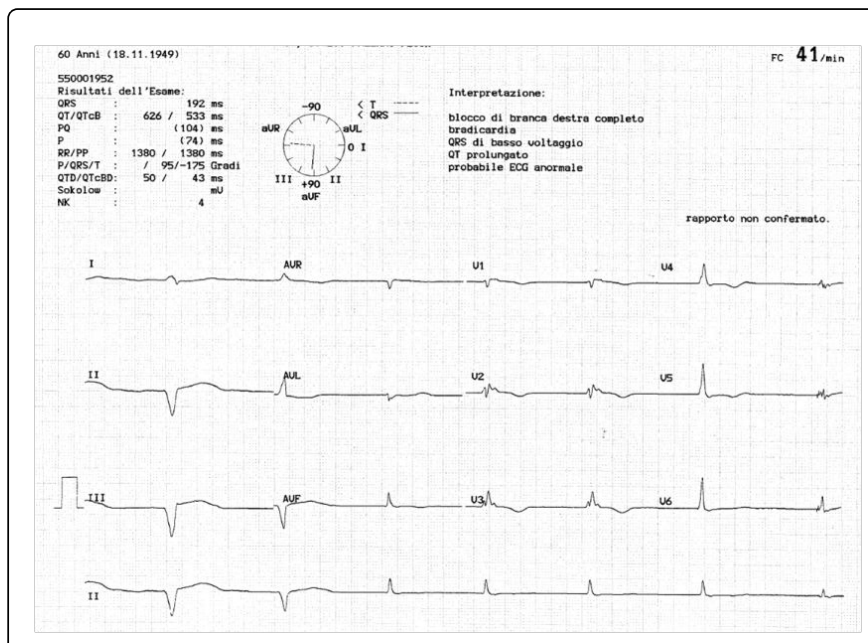

Figure 1: ECG: Atrial fibrillation, epsilon waves in right precordial leads and inverted $\mathrm{T}$ waves in V1-V5.

Microscopic examination revealed transmural adipose infiltration with hypertrophic and degenerated myocytes. Subendocardial fibrosis was also seen. Similar pathological findings, although of smaller extension, were also detected in left ventricle (Figure 2). 


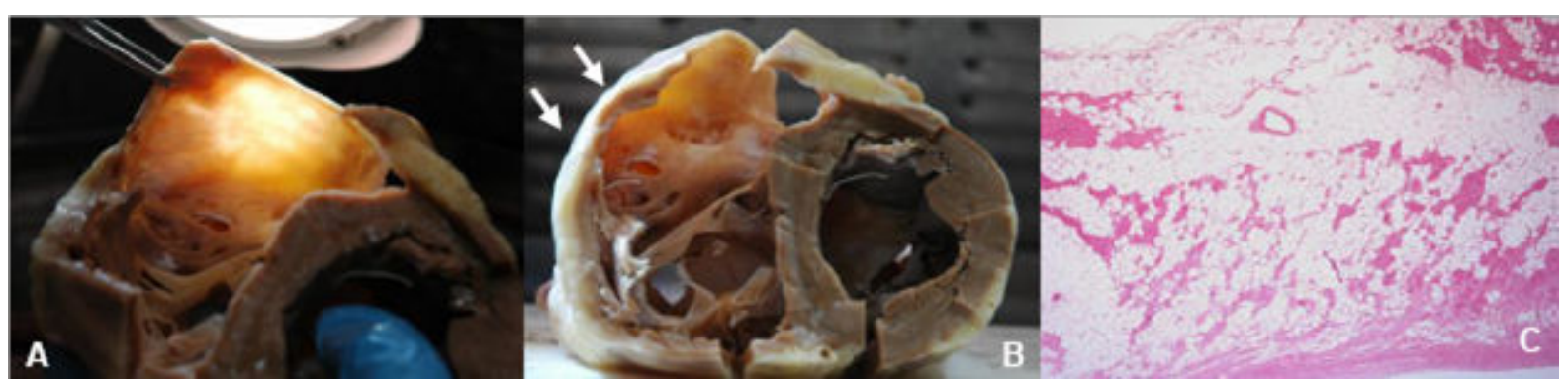

Figure 2: Right ventricle outflow tract wall thinning at transillumination (panel A). Total fibro-fatty replacement of right ventricular myocardium (panel B-C)

\section{Case 2}

This is a 43-year-old female with a past diagnosis of post-partum cardiomyopathy (1994) characterized by episodes of non-sustained VT. In 2009 an echocardiography showed severe dilatation and systolic dysfunction of the right ventricle (FAC 25\%; TAPSE $13 \mathrm{~mm}$ ) with aneurysmatic areas and diastolic bulging of apex and infero-lateral wall. Left ventricle was dilated and hypo-akinetic (EF 33\%) too. Cardiac magnetic resonance (MRI) confirmed our suspicious of ARVC with biventricular involvement and evidence of fibrosis of right ventricle and of basal and median segment of anterolateral and inferior wall. Implantable cardioverted-defibrillator (ICD) implantation was performed. Many episodes of cardiac decompensation occurred so she was hospitalized for heart transplant work up. At RHC we founded: pulmonary artery pressure: 38/18/28 $\mathrm{mmHg}$, right atrium pressure: 10 $\mathrm{mmHg}$, pulmonary capillary wedge pressure: $24 \mathrm{mmHg}$, cardiac index $1.9 \mathrm{~L} / \mathrm{min} / \mathrm{mq}$ while cardiopulmonary exercise test showed a low maximal oxygen consumption $(10.4 \mathrm{~mL} / \mathrm{kg} / \mathrm{min})$.

Considering hemodynamic instability with end-stage biventricular failure, NYHA class III, despite maximal tolerated therapy with furosemide $50 \mathrm{mg}$, carvedilol $12,5 \mathrm{mg}$, losartan $50 \mathrm{mg}$, spironolactone $25 \mathrm{mg}$ and amidarone $200 \mathrm{mg}$, she was inserted in waiting list and, on 3 April 2012 was transplanted. Post-operative course was regular. The findings of ARVC were founded at anatomo-pathological examination (Figure 3). Explanted heart examination revealed a dilated and thinwalled right ventricle. Especially in the infero-basal region and in the apex, the RV wall was translucent, extremely thinned (apical wall thickness $1 \mathrm{~mm}$ ) and infiltrated by adipose tissue. In LV fibrofatty replacement of myocardium was limited to posterior wall while in lateral wall a focal two-layered area with an epicardial compacted and a thick endocardial non-compacted layer was described. Microscopic examination showed a severe degeneration of myocytes, repaired by fibro-fatty replacement.

\section{Discussion}

Arrhythmogenic right ventricular cardiomyopathy/dysplasia is an heart muscle disease that predominantly affects the right ventricle and predisposes to ventricular arrhythmias, sudden cardiac death and heart failure [1-4].

Despite the modified Task Force criteria [5], diagnosis of ARVC is still problematic and often made only by pathological examination during autopsy after unexplained sudden death. Cardiac MRI allows to characterize structural abnormalities [6] but its use is limited by ICD implantation. The growing knowledge regarding arrhythmic outcome, risk factors, and life-saving therapeutic interventions, make it particularly timely to critically address and place into perspective the issues relevant to the clinical management of ARVC/D patients [7].

Natural history and prognostic predictors are also not well understood $[8,9]$. Some patients are asymptomatic with typical RV structural changes and can experience sudden death, some other

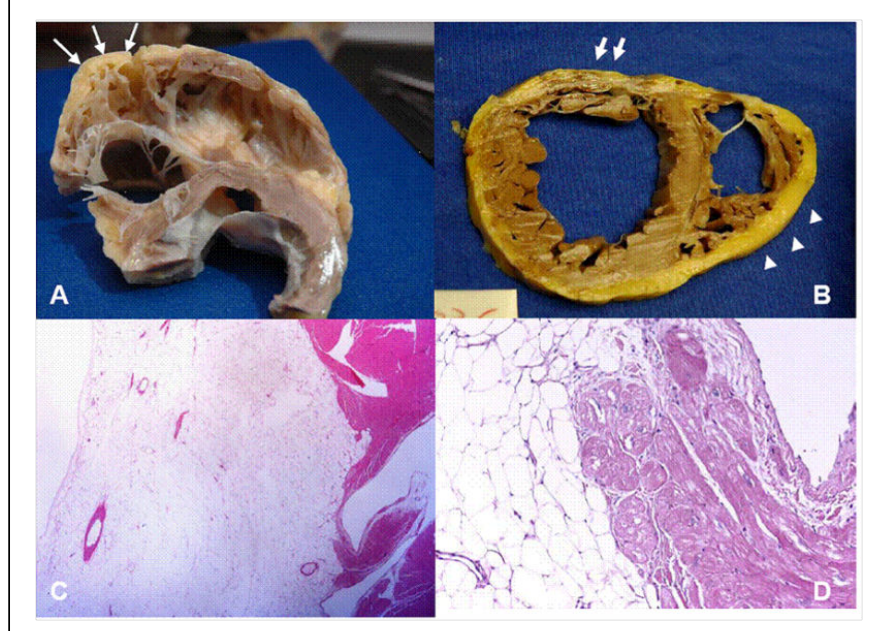

Figure 3: Panel A: Transmural fibrofatty replacement in infundibulum. Panel B: A focal area of adipose infiltrate/infiltration in left ventricular posterior wall (arrows) and diffuse adipose substitution in right ventricular wall (arrowheads). Panel C, D: Transmural adipose infiltration with degenerated and hypertrophic myocytes.

develop signs of right congestive ventricular failure. End stage biventricular failure can also occur in selected cases. The frequency of progression to heart failure is actually still unknown [10].

At the best of our knowledge, indications and timing of transplantation for ARVC are lack and only few cases are described in literature [11,12]. Refractory RV failure, LV involvement and recurrence of ventricular arrhythmias had been recognized as prognostic predictors. These subsets of patients should be considered as cardiac transplant candidates.

We presented two cases of ARVC with different clinical and anatomo-pathological pictures. The first patient had severe RV heart 
Citation: Gesaro GD, Minà C, Ruperto C, Liotta R, Scardulla C, et al. (2016) Arrhythmogenic Right Ventricular Cardiomyopathy and Heart Transplantation: Two Cases. J Cytol Histol 7: 1000388. doi:10.4172/2157-7099.1000388

Page 3 of 3

failure with mild LV involvement and persistent electrical instability, despite drug therapy, for which he had been subjected to repeated ablation procedures. The clinical picture of the second patient was instead characterized by refractory congestive heart failure with biventricular involvement. Our cases demonstrate that Heart transplant is a real therapeutic option and offer to us the possibility to confirm the diagnosis and better understand pathological features of the disease.

\section{References}

1. Basso C, Thiene G, Corrado D, Angelini A, Nava A, et al. (1996) Arrhythmogenic right ventricular cardiomyopathy. Dysplasia, dystrophy, or myocarditis? Circulation 94: 983-991.

2. Corrado D, Basso C, Thiene G, McKenna WJ, Davies MJ, et al. (1997) Spectrum of clinicopathologic manifestations of arrhythmogenic right ventricular cardiomyopathy/dysplasia: a multicenter study. J Am Coll Cardiol 30: 1512-1520.

3. Corrado D, Basso C, Thiene G (2000) Arrhythmogenic right ventricular cardiomyopathy: diagnosis, prognosis, and treatment. Heart 83: 588-595.

4. Basso C, Corrado D, Marcus FI, Nava A, Thiene G (2009) Arrhythmogenic right ventricular cardiomyopathy. Lancet 373: 1289-1300.

5. Marcus FI, McKenna WJ, Sherrill D (2010) Diagnosis of arrhytmogenic right ventricular cardimyopathy/dysplasia. proposed modification of the task force criteria. European Heart Journal 31: 806-14.
6. Kimura F, Matsuo Y, Nakajima T, Nishikawa T, Kawamura S, et al. (2010) Myocardial fat at cardiac imaging: how can we differentiate pathologic from physiologic fatty infiltration? Radiographics 30: 1587-602.

7. Corrado D, Wichter T, Link MS, Hauer R, Marchlinski F, et al. (2015) Treatment of arrhythmogenic right ventricular cardiomyopathy/ dysplasia: an international task force consensus statement. Eur Heart J 36: 3227-37.

8. Pinamonti B, Dragos AM, Pyxaras SA, Merlo M, Pivetta A, et al. (2011) Prognostic predictors in arrhytmogenic right ventricular cardimyopathy: results from a 10-years registry. European Heart Journal 32: 1105-13.

9. Lemola K, Brunckhorst C, Helfenstein U, et al. (2005) Predictors of adverse outcome in patients with arrhythmogenic right ventricular dysplasia/cardiomyopathy: long term experience of a tertiary care centre. Heart 91: 1167-72.

10. Dalal D, Nasir K, Bomma C, Prasaka K, Tandri H, et al. (2005) Arrhythmogenic Right Ventricular Dysplasia: a United States Experience. Circ 112: 3823-32.

11. Gilljam T, Claes-Hakan B (2009) Right ventricular cardiomyopathy: timing of heart transplantation in Uhl's anomaly and arrythmogenic right ventricular cardiomyopathy. European Journal of Heart Failure 11: 106-9.

12. Yoda M, Minami K, Fritzsche K, Tendrich G, Schulte-Eistrup S, et al. (2005) Three Cases of Orthotopic Heart Transplantation for Arrhythmogenic Right Ventricular Cardiomyopathy. Ann Thorac Surg 80: 2358-60. 